\title{
ESTUDIOS
}

\section{Condiciones laborales de los inmigrantes en la Unión Europea: un estudio comparado}

\section{José Antonio Ariza Montes \\ Alfonso Carlos Morales Gutiérrez \\ Emilio Morales Fernández'}

Palabras clave: Condiciones laborales, inmigración, UE, regresión logística.

Key words: Working conditions, immigration, EU, logistic regression.

Mots clés: Conditions de travail, immigration, UE, régression logistique.

\section{Introducción}

La principal novedad acerca del debate sobre la inmigración en Europa es que, en nuestra opinión, no debería existir debate alguno. Tan solo se precisa echar un vistazo a la evolución de las pirámides de población de los principales países de la Unión Europea, para comprender y aceptar que los inmigrantes no suponen ningún problema para el estado del bienestar sino que, por el contrario, resultan indispensables para sostener el crecimiento económico sobre el que se fundamenta el modelo europeo del bienestar ${ }^{2}$.

\footnotetext{
' Departamento de Economía General, Ciencias Jurídicas y Sociología. Facultad de Ciencias Empresariales - ETEA.

2 Un dato en formato flash ayuda a asimilar este argumento: en 2008 en España, los jóvenes de 16 años que se incorporaron al mercado laboral fueron la mitad de los que lo hacían cuando estos nacieron hace 16 años. En este sentido, Espínola (2006) pone de manifiesto la importante y creciente implicación entre la inmigración y el funcionamiento del sistema económico español en el lustro 2000-2005,
} 
Durante las últimas décadas, la población de los 27 países que actualmente integran la Unión Europea ha crecido de manera notable, pasando de cuatrocientos millones en 1960 a quinientos en 2009. Sin embargo, tal y como se constata a continuación, el patrón de esta evolución no ha sido ni homogéneo ni equilibrado. La estructura de crecimiento de cualquier zona geográfica presenta dos componentes fundamentales, uno de tipo natural y otro de carácter migratorio. En este sentido, hasta finales de la década de los ochenta, el crecimiento de la población europea se cimentaba sobre todo en el componente natural, invirtiéndose la tendencia a comienzos de los noventa, debido al descenso de la tasa de fertilidad (si en 1960 la media de hijos era de 2,5, en 1993 esta se situaba en 1,53) y al progresivo aumento de los flujos migratorios.

En algunas regiones europeas, un saldo vegetativo negativo ha sido compensado con un balance migratorio de signo positivo. Este hecho ha sido más acusado en Alemania del Este, Austria, el norte de Italia y Eslovenia, así como en el sur de Suecia y ciertas regiones de España, Grecia y el Reino Unido. La situación contraria es casi inexistente, a excepción del norte de Polonia donde un saldo migratorio negativo se ha visto compensado por el crecimiento natural de la población. En otros países como Irlanda, Benelux, muchas regiones de Francia y en algunas de España, el crecimiento natural de la población ha venido acompañado de un aumento fundamentado en la llegada de los inmigrantes. Por último, en la Alemania del Este, Lituania y Letonia, así como en algunas regiones de Polonia, la República Checa, Eslovaquia, Hungría y Rumania, ambos componentes poblacionales, tanto el natural como el migratorio, han experimentado un descenso que se ha traducido en pérdidas más o menos significativas de población.

Como se puede constatar, la inmigración constituye un fenómeno de gran importancia para comprender el desarrollo y evolución de las naciones que integran a día de hoy la UE. Los movimientos migratorios -intra y extracomunitarios- han contribuido en ciertos casos a mitigar los perniciosos efectos que acechan a la despoblación en algunas regiones, mientras que en otros han multiplicado el crecimiento vegetativo, cambiando la fisonomía de muchos países y derribando las catastróficas

afirmando que los rasgos más destacados de este dinamismo no se explican fehacientemente sin tener en cuenta el fuerte flujo de inmigrantes de los últimos años y el boom demográfico que ha provocado. Los flujos de producto y empleo, renta, consumo final y ahorro, formación de capital, o balanza de pagos, entre otras cosas, han estado influidos por la creciente población residente que la inmigración ha provocado.

${ }^{3}$ Una tasa de 2,1 niños por mujer se considera el nivel mínimo de reemplazo de la población. 
previsiones sobre evolución de las pirámides de edad de los mismos ${ }^{4}$.

Pese a que la configuración contemporánea de Europa no podría entenderse al margen del fenómeno migratorio, los estudios sobre este asunto son escasos y de alcance muy limitado, más aún en el ámbito de la UE. Esta circunstancia es debida, entre otros motivos, a la dificultad para obtener información fiable y homogénea que permita cuantificar el impacto de la inmigración en cada uno de los países de la Unión debido, por un lado, al elevado número de personas que se encuentran en situación irregulary, por otro, a las distintas fuentes de información existentes, carentes en muchos casos de uniformidad de criterio incluso dentro de un mismo país ${ }^{5}$.

Precisamente, el objeto del presente trabajo es analizar a la población inmigrante en el contexto de la Unión Europea aterrizando en uno de los aspectos más polémicos del fenómeno: la integración de estas personas en el mercado de trabajo. Para ello, el documento se estructura en los siguientes apartados. En primer lugar se hará una referencia a aquellos postulados teóricos que fundamentan los detonantes, sobre todo económicos, de los movimientos migratorios para, a reglón seguido, aludir al impacto de la inmigración sobre el mercado laboral. Posteriormente, se expondrán los principales resultados obtenidos, mediante el análisis de una encuesta a nivel europeo, donde se ponen de manifiesto las condiciones laborales de la población inmigrante -intra y extracomunitaria- en comparación con los ocupados nacionales, con el objeto de conocer en profundidad cómo se produce la inserción laboral de los inmigrantes económicos en el entorno de la UE, así como las posibles discriminaciones a las que se ven sometidos ${ }^{6}$. El trabajo finaliza con las conclusiones y la bibliografía correspondiente.

${ }^{4}$ Un estudio demográfico de la División de Población de Naciones Unidas preveía que en 2050 España habría perdido casi el $22 \%$ de su población, reduciéndose el número de habitantes de 40 millones a 31,2 .

${ }^{5} \mathrm{~A}$ modo de ejemplo, en España se pueden citar entre otras las Estadísticas de Variaciones Residenciales (EVR) del INE, los censos y padrones de los ayuntamientos, los permisos de residencia de la Dirección General de Policía, los permisos de trabajo del Ministerio de Trabajo y Asuntos Sociales, las afiliaciones a la Seguridad Social, los contratos registrados en el Instituto Nacional de Empleo o la evolución de la población extranjera activa y ocupada de la Encuesta de Población Activa del INE.

${ }^{6}$ Martínez (2006) considera que para conocer si se está produciendo una integración efectiva de los inmigrantes en la sociedad receptora es necesario comparar los procesos que viven los no nacidos en el país de acogida, con los autóctonos nacionales o con los nacionalizados nacidos en otros países e incluso con los inmigrantes que se encuentran en situación irregular. El hecho es que sin comparar es difícil hablar de integración. En este sentido, el presente artículo pretende aportar algo de luz en relación con uno de los ámbitos más críticos para una integración real: el mercado de trabajo. 


\section{Factores explicativos de los fenómenos migratorios}

Sin ánimo de exhaustividad, hay que indicar que la mayoría de los investigadores sobre esta materia coinciden en que las migraciones se explican en gran medida por la combinación de dos elementos, lo que se conoce como "efecto expulsión" (push) y "efecto llamada" (pull). La clave para comprender adecuadamente en qué consisten estos efectos y su complementariedad es la enorme desigualdad que existe en el ámbito internacional. Tal y como indica el Servicio Jesuita a Migrantes (2008), las condiciones de vida reales y cotidianas de la mayor parte de la humanidad todavía no permiten un desarrollo humano ni siquiera mínimamente aceptable. Según este documento, el subdesarrollo tiene causas concretas cuyo origen hay que buscar, en muchas ocasiones, si no en todas, en los países enriquecidos y empobrecedores del Norte desarrollado. En este sentido, nuestros "países desarrollados" son los auténticos causantes del efecto expulsión que da lugar a los actuales movimientos migratorios. Al empobrecimiento del Sur corresponde el enriquecimiento del Norte, y este abismo de la desigualdad -o dos caras de una sola realidad- configura el escenario en el que las migraciones surgen como estrategia de desarrollo personal y familiar.

Desde esta perspectiva, las migraciones se explicarían fundamentalmente por la presión ejercida por los factores push que incitan a los trabajadores a abandonar sus países de origen, aunque muchos investigadores sugieren que estos por sí solos no son suficientes. Ni mucho menos, también se deben tener en consideración los factores pull, en la medida en que las naciones anfitrionas deben resultar atractivas para atraer a los emigrantes, facilitando su integración en los mercados de trabajo respectivos. No obstante, hoy por hoy, se puede afirmar que buena parte de los movimientos migratorios internacionales se nutren sobre todo de personas que se trasladan desde países en vías de desarrollo hacia países más desarrollados (migraciones Sur-Norte o Este-Oeste) con el objetivo de encontrar un empleo que les permita mejorar su situación económica y la de sus familias (Carrasco 1999)7. Bajo este prisma, la Unión Europea se configura como un área geográfica con inconcusa capacidad de atracción de personas procedentes tanto de países ajenos a la misma como, en ausencia de restricciones legales a la inmigración tras el espacio Schengen, de movimientos internos procedentes de las naciones miembro con niveles de renta más bajos hacia los países con salarios y condiciones laborales y sociales más competitivos: tasas de desempleo, coste de la vida y de los

\footnotetext{
${ }^{7}$ En un sentido parecido se pronuncia Zimmermann (2005) al declarar que las decisiones de migración vienen determinadas por las diferencias regionales en prosperidad. Para una revisión en profundidad de la literatura sobre este asunto se puede consultar el trabajo de Baver y Zimmermann (1998).
} 
servicios públicos, seguridad y estabilidad laboral... Precisamente, en el estudio empírico que se desarrolla en el apartado 4 se hace una distinción entre estos dos colectivos bajo la hipótesis de que el grupo de inmigrantes extracomunitarios es más compacto, mientras que los inmigrantes intracomunitarios son más heterogéneos dado que, por ejemplo, poco tienen que ver entre sí un ingeniero alemán que trabaje en la construcción del Airbus en España con un rumano que realice tareas agrícolas en nuestro país.

El argumento previo parte de la hipótesis de que los trabajadores individuales tratan de maximizar su utilidad, desplazándose a los países que ofrezcan mejores oportunidades de empleo y condiciones laborales. De este modo, la precaria situación de desempleo o subempleo del país de origen se configuraría como el principal factor de expulsión que explicaría el abandono del lugar de residencia habitual. En este sentido, diversos estudios han analizado la vinculación entre crisis económicas y movimientos migratorios en diferentes zonas geográficas del mundo, como por ejemplo en Latinoamérica (Acosta y Atienza, 2004) o África (Aubarell y Aragall, 2004) ${ }^{8}$.

Pero como se indicaba anteriormente, este factor por sí solo no es suficiente, sino que debe venir acompañado de unas expectativas favorables con respecto al país de destino. Así, la teoría del capital humano de Sjaastad (1962) predice que los trabajadores adoptan la decisión de emigrar evaluándola en términos de inversión, es decir, sopesando las expectativas de beneficio y costes asociados, de tal manera que la emigración sólo se producirá cuando la ganancia neta esperada sea positiva. En este análisis vital no todo se mide en términos de coste monetario, sino que también existe una vertiente psicológica asociada, entre otras cosas, al coste que implica la separación familiar y del entorno socio-cultural de referencia?.

En este proceso de reflexión introspectiva juega un papel determinante el diferencial existente entre países emisores y receptores de población migrante en

\footnotetext{
${ }^{8}$ Aunque un mayor desarrollo teórico excedería, evidentemente, del ámbito de este artículo, no podemos dejar de mencionar en este momento que los factores de expulsión y atracción encuentran su fundamentación científica en los llamados enfoques del crecimiento económico o del desarrollo (Lewis, 1954; Harris y Todaro, 1970; Massey y otros, 1993; o Borjas, 1994 entre otros).

9 De acuerdo con esta teoría, la probabilidad de migración decrecería con la edad, ya que las expectativas de ganancia son menores a medida que las personas son mayores; debería aumentar entre los individuos mejor formados, dada su mayor capacidad para proveerse y procesar información; y debería descender con la distancia, ya que la información sobre las condiciones del mercado laboral del país de destino serán mejores para localizaciones más próximas.
} 
distintos aspectos tales como la renta per cápita, oportunidades económicas (Borjas, 1994 y 1999), prestaciones del estado del bienestar ${ }^{10} \mathrm{o}$ incluso ciertos aspectos demográficos como el envejecimiento de la población del norte frente al sur (Zimmermann, 1994, 1995a).

Desde el punto de vista de los detonantes de atracción, Argerey y otros (2005) identifican tres factores principales: el mercado de trabajo dual, las directrices en política migratoria del país anfitrión y el funcionamiento de la economía informal. Por un lado, según la teoría del mercado de trabajo dual, los inmigrantes abandonaría sus países de origen atraídos por la escasez de mano de obra nativa en determinados sectores productivos del país de destino (Piore, 1979)" ${ }^{1}$. Por otro, la laxitud o rigorismo de la normativa legal del país receptor en materia de extranjería suscita un efecto, bien de atracción o de rechazo, respecto a los movimientos migratorios internacionales. Finalmente, otros autores como Pajares (2004) limitan el factor restrictivo de la legislación, siempre y cuando en el mercado laboral de destino exista un elevado componente de economía sumergida o irregular. Esta última aproximación preocupa especialmente a la Unión Europea, reconociendo explícitamente que las restricciones en el acceso al mercado de trabajo pueden ensanchar el problema del trabajo no declarado (Comisión Europea, 2006).

\section{Inmigración y mercado de trabajo}

A nivel europeo no existe aún una proporcionalidad suficiente entre la importancia del fenómeno migratorio y la investigación empírica sobre este asunto. Por un lado, porque la magnitud de los flujos es reciente, descompensada entre países y dinámica-dadas las últimas ampliaciones en el seno de la UE que han transformado automáticamente a inmigrantes extracomunitarios en ciudadanos europeos de pleno derecho-y, por otro, por las limitaciones de las bases de datos disponibles. En el

\footnotetext{
${ }^{10}$ Según algunos autores (Aparicio y Tornos, 2002) la prestación de servicios públicos -sanitarios, educativos, protección social, etc.- de forma más amplia y generosa en el país de destino puede constituir un factor de atracción para el posible emigrante (Zimmermann, 1994; Borjas, 2002), aunque ello estaría también sujeto a la distancia geográfica entre el país elegido de destino y el país de origen (Borjas, 1999).

1 Sólo de este modo se explica que exista en España un catálogo oficial de ocupaciones de difícil cobertura en el que, entre muchas otras, en el $4^{\circ}$ trimestre de 2009 se necesitaban en ciertas provincias mecánicos ajustadores de motores, esquiladores, técnicos de protección civil, peluqueros de caballero, caldereros-tuberos o auxiliares de óptica.
} 
caso concreto del mercado de trabajo, los estudios se han centrado principalmente en analizar tanto el posible impacto sobre los trabajadores nativos -oportunidades de empleo, condiciones laborales, salarios...-, como la asimilación laboral de los inmigrantes en el mercado laboral del país de destino (Lalonde y Topel, 1997; Borjas, 1999; Sanromá y otros, 2006).

Pese a la impresión generalizada en algunos estratos sociales de que la inmigración aumenta el desempleo entre los trabajadores autóctonos, a la vez que degrada las condiciones laborales del país receptor, lo cierto es que los estudios realizados hasta el momento no han encontrado impactos negativos significativos en este sentido (Zimmermann, 2005; Commander y otros, 2006). En el caso español, Carrasco y otros (2004) analizaron el impacto de la inmigración legal e ilegal de la segunda mitad de los noventa sobre las tasas de empleo de los trabajadores nativos, hallando una elasticidad de $-0,17$ para la primera y nula para el total (Sanromá y otros, 2006). En una línea de investigación parecida, Amuedo-Dorantes y de la Rica (2005) investigaron las decisiones de residencia de los inmigrantes llegados entre 1999 y 2004, concluyendo que estos se trasladaban hacia las regiones con mayores tasas de empleo, contribuyendo, de esta forma a reducir las diferencias en las tasas de paro regionales, circunstancia que no suele ser habitual entre la población autóctona dada la escasa propensión de esta al cambio de residencia.

Herrarte y otros (2007) también reconocen la controversia que existe en la literatura internacional acerca de los efectos de la inmigración sobre el mercado laboral de destino. Según estos autores, la mayoría de los estudios realizados en Estados Unidos y Europa han tratado de contrastar una relación negativa entre salarios y el número o la proporción de inmigrantes extranjeros, si bien la mayoría de ellos han fracasado en su intento. Sobre este asunto, y aplicado al caso concreto de los Estados Unidos, se puede consultar la renombrado investigación de Card (1990) o los trabajos recopilatorios de Friedberg y Hunt (1995), Borjas y otros (1997) y Borjas (1999).

En el ámbito de los países europeos desarrollados, más acorde con los objetivos de la presente investigación, los resultados no difieren de modo significativo. Así, el trabajo de De New y Zimmermann (1994) realizado en la Alemania de la década de los ochenta obtiene resultados similares a los de Jaeger (1996) para Estados Unidos en las mismas fechas, encontrando que la inmigración afecta negativamente a los trabajadores poco cualificados y positivamente a los más cualificados. Donaghey y Teague (2006) también observan cierta tendencia a la reducción de los salarios pero sólo entre los trabajadores no cualificados. En un estudio de Winkelmann y Zimmermann (1992) también se concluye que el impacto negativo 
de la inmigración sobre la duración del desempleo para Europa es pequeño en el corto plazo y en el de Greenwood y McDowell (1986) que esta brevedad del impacto se produce asimismo sobre los salarios. Por su parte, Pischke y Velling (1997) realizan un análisis con datos espaciales para 167 regiones en Alemania y tampoco encuentran efectos negativos de la inmigración sobre el empleo.

En definitiva, hasta el momento no se puede asegurar que existan evidencias empíricas suficientes como para afirmar con carácter general que existe una relación directa entre la inmigración y las condiciones laborales de los trabajadores nativos, posiblemente, porque como se verá a continuación, los trabajadores autóctonos y foráneos forman dos colectivos claramente diferenciados desde el punto de vista laboral.

\section{Estudio empírico}

En la sociedad del siglo XXI, el trabajo se configura como la piedra miliar sobre la que se sustenta la propia constitución del ser humano como persona libre, autónoma y responsable. Desde esta óptica, tal y como indican Charro y Benlloch (2006), resulta lógico que la estrategia predominante de la mayoría de los inmigrantes sea la integración en las naciones de acogida a través del empleo. Bajo este prisma, el auténtico reto de cualquier sociedad donde la inmigración supone un instrumento de aporte de mano de obra es conseguir el adecuado equilibrio entre la presión de los flujos migratorios y las necesidades concretas del mercado de trabajo de acogida.

En este sentido, analizar las características del empleo de la población inmigrante y compararlas con el compendio de derechos y obligaciones que poseen los trabajadores nacionales, ayudará a comprender mejor en qué condiciones se produce la integración efectiva del trabajador extranjero en el mercado laboral del país anfitrión. ¿ Disfrutan ambos colectivos de las mismas oportunidades? ¿Los niveles de seguridad en el empleo y protección social son los mismos? ¿Las condiciones laborales de los inmigrantes intracomunitarios se parecen más a las de los extranjeros procedentes de países al margen de la UE o, por el contrario, son similares a las que disfrutan los trabajadores autóctonos? Los resultados del estudio que se exponen a continuación -realizado con una muestra de trabajadores en el ámbito europeo- pretenden dar respuesta a algunos de estos interrogantes. 


\section{I. La muestra}

Los datos empleados en la presente investigación se han extraído de la IV Encuesta Europea de Condiciones de Trabajo, realizada durante el otoño de 2005 por la Fundación Europea para la Mejora de las Condiciones de Vida y de Trabajo. Esta encuesta de periodicidad quinquenal analiza las condiciones de trabajo en los 27 países de la Unión Europea ${ }^{12}$.

La población objeto de investigación son todas las personas con 15 años o más cuyo lugar habitual de residencia sea alguno de los estados miembros de la Unión Europea y que durante el período de referencia estuvieran ocupados, ya sea por cuenta propia o ajena. En algunos países se aplica un intervalo de edad diferente, ya sea por el límite inferior (en España y Reino Unido la edad mínima es de 16 años), o bien por el superior (en Dinamarca, Eslovenia, Letonia, Hungría, Finlandia y Suecia se establece como límite la edad de 74 años).

El trabajo de campo se realizó entre septiembre y noviembre de 2005, con una duración que oscila entre los diferentes países pero que, por término medio, fue de siete semanas. En el trabajo de campo participaron 2.745 entrevistadores que visitaron 72.300 hogares, obteniendo un total de 29.766 encuestas válidas.

Dados los objetivos de la presente investigación, se obtuvo una submuestra de 1.400 personas, de las cuales el $35,8 \%$ eran nacionales, un $29,4 \%$ eran inmigrantes intracomunitarios y el $34,9 \%$ restante eran inmigrantes procedentes de países ajenos a la Unión Europea ${ }^{13}$.

Tomando como referencia la muestra total hay que indicar que el $50,6 \%$ de los participantes son hombres y el $49,4 \%$ mujeres. La edad media de los encuestados es de 42,13 años (41,99 en los hombres y 42,27 entre las mujeres). El porcentaje de encuestados que vive en pareja alcanza el $62,68 \%$, siendo superior entre los hombres $(66,05 \%)$ que entre las mujeres $(59,22 \%)$. Además, un $34,6 \%$ del total de encuestados tiene hijos menores de 15 años conviviendo en el hogar, mientras que

\footnotetext{
${ }^{12}$ Aunque la encuesta original incluye también a ciudadanos de Turquía, Croacia, Noruega y Suiza, el interés de este estudio se centra únicamente en el ámbito de la UE.

${ }^{13}$ En sintonía con lo que se comentó en la introducción a este trabajo hay que recordar la dificultad existente para encontrar fuentes fiables de información sobre la población inmigrante $y$, menos aún, referidas al mercado laboral y sus condiciones. De todos modos, no se puede olvidar que el objeto de estudio son los inmigrantes -comunitarios o no- que trabajan en algún país de la Unión Europea, cuyo peso sobre el total de la población europea apenas superaba en 2004 el 5\% del total.
} 
un $26,1 \%$ convive con hijos mayores de esa edad. Por último, el $11,4 \%$ declara no tener estudios o haber cursado solo estudios primarios $(11,8 \%$ entre los hombres frente al $11,1 \%$ de las mujeres), un $61,4 \%$ tiene formación secundaria $(62,6 \%$ y $60,9 \%$ respectivamente) y un $26,8 \%$ ha completado estudios universitarios: $25,6 \%$ frente al $28,0 \%$.

\subsection{Análisis de resultados}

El objetivo general de este trabajo es profundizar en las condiciones laborales de la población inmigrante en la UE en comparación con los ocupados autóctonos, de tal modo que se ponga de manifiesto si existen o no determinadas características del empleo que sirven para diferenciar a tales colectivos. Para lograr este fin se utiliza en primer lugar un análisis de tablas de contingencia y Chi-cuadrado de Pearson, con el objeto de examinar la posible relación bivariante entre la variable nacionalidad y un conjunto de variables agrupadas en tres categorías: a) contexto y datos estructurales, b) condiciones de trabajo, y c) discriminación y satisfacción. Además, este primer análisis servirá de preparación para el análisis multivariante que se realizará posteriormente, desarrollando un modelo de regresión logística donde se ponga de manifiesto el efecto conjunto que las variables independientes, con una capacidad de predicción estadísticamente significativa, ejercen sobre la nacionalidad de los individuos encuestados.

\subsection{I.Análisis bivariante}

\subsection{I. Contexto y datos estructurales}

Tal y como se puede apreciar en la tabla 1, la aplicación del contraste de Pearson a un nivel de significación de 0,05 indica que no existen diferencias significativas en la distribución de las tres categorías de encuestados por razón de sexo, algo que sí ocurre en relación con la edad y el nivel de formación. De esta manera, la edad de los inmigrantes extracomunitarios es más joven en comparación con los otros dos grupos objeto de análisis (uno de cada cuatro tiene entre 15 y 29 años y sólo el 15,2\% tiene más de 50 años) confirmándose de este modo que la inmigración atrae sobre todo a una mano de obra que contribuye a aumentar la población activa en la Unión Europea. Por otra parte, los inmigrantes intracomunitarios se distribuyen de forma similar a los nacionales en el intervalo de edad más joven, aunque surgen diferencias en los tramos superiores, concentrándose gran parte de este colectivo en la cohorte de 30 a 49 años, posiblemente porque 
la movilidad de estos trabajadores se produjo antes que la de los inmigrantes extracomunitarios.

Por lo que respecta al nivel de formación de los inmigrantes se observan diferencias significativas en ambos grupos con respecto a la población autóctona. Así, aunque el porcentaje de personas que llegan a trabajar a la UE sin estudios o sólo habiendo cursado estudios primarios es más elevado $(14,8 \%$ del total en inmigrantes intracomunitarios y $11,8 \%$ en extracomunitarios) en comparación con los nacionales, también es muy significativa la llegada de trabajadores cualificados con estudios universitarios ( $31,6 \%$ y $24,5 \%$, respectivamente), aunque como se verá más adelante esto no significa que dichas personas desarrollen trabajos remunerados en sintonía con su nivel de cualificación.

La distribución sectorial también presenta diferencias dignas de reseña. Como se puede comprobar en la tabla 1 , los inmigrantes acceden al empleo fundamentalmente a través del sector servicios $(68,0 \%$ en el caso de los intracomunitarios y $66,1 \%$ en los extracomunitarios, datos que contrastan con el $59,7 \%$ de los ocupados nacionales), aunque también se observa una presencia notable de inmigrantes ajenos a la UE empleados en el sector industrial. Por otra parte se constata que la administración pública está vetada en general para los inmigrantes extracomunitarios (no llega al $9 \%$ del total el porcentaje de personas que trabajan para el sector público), una restricción menos significativa que en el caso de los intracomunitarios (el 17,2\% trabajan en este sector) aunque todavía muy lejos del peso que el empleo público supone para los trabajadores autóctonos (casi uno de cada tres ocupados).

La investigación también pone de manifiesto que la proporción de personas que trabajan por cuenta propia es muy similar entre los distintos colectivos $115,5 \%$ en nacionales, $15,1 \%$ en inmigrantes intracomunitarios y $13,0 \%$ en inmigrantes extracomunitarios), hasta el punto de que no se han hallado diferencias estadísticamente significativas $\left(\chi^{2}: 3,485 ;\right.$ Sig. 0,480$)$.

Asimismo, el tipo de ocupación que desempeñan los nacionales y los inmigrantes intracomunitarios es similar, con una mayoría de personas realizando tareas de "cuello blanco" -tales como dirección de empresas, profesionales, técnicos, administrativos, dependientes...- frente a las tareas de "cuello azul" (trabajadores agrícolas, operadores, artesanos...). Esta situación se invierte al observar las ocupaciones que ejecutan los inmigrantes extracomunitarios: $57,9 \%$ con tareas de "cuello azul" y $42,1 \%$ en actividades de "cuello blanco", lo que pone de manifiesto una nueva discriminación en el acceso al empleo de estos sujetos, ya que como se indicó anteriormente no existen diferencias atribuibles al nivel de formación de estos colectivos que justifiquen dicha situación. 
TABLA I. El individuo en la empresa

\begin{tabular}{|c|c|c|c|c|c|}
\hline Variables & Nacional & $\begin{array}{c}\text { Inmigr. } \\
\text { intracomu- } \\
\text { nitario }\end{array}$ & $\begin{array}{l}\text { Inmigr. } \\
\text { extraco- } \\
\text { munitario }\end{array}$ & $\chi^{2}$ & Sig. \\
\hline \multicolumn{6}{|l|}{ Sexo } \\
\hline Hombre & $47,1 \%$ & $51,6 \%$ & $53,5 \%$ & \multirow{2}{*}{4,228} & \multirow{2}{*}{ n.s. } \\
\hline Mujer & $52,9 \%$ & $48,4 \%$ & $46,5 \%$ & & \\
\hline \multicolumn{6}{|l|}{ Edad } \\
\hline $15-29$ & $19,2 \%$ & $19,1 \%$ & $24,6 \%$ & \multirow{3}{*}{35,75} & \multirow{3}{*}{0,000} \\
\hline $30-49$ & $51,5 \%$ & $62,6 \%$ & $60,2 \%$ & & \\
\hline $50+$ & $29,3 \%$ & $18,3 \%$ & $15,2 \%$ & & \\
\hline \multicolumn{6}{|l|}{ Formación } \\
\hline Sin estudios/primarios & $8,4 \%$ & $14,8 \%$ & $11,8 \%$ & \multirow{3}{*}{19,58} & \multirow{3}{*}{0,000} \\
\hline Estudios secundarios & $66,5 \%$ & $53,6 \%$ & $63,7 \%$ & & \\
\hline Estudios universitarios & $25,1 \%$ & $31,6 \%$ & $24,5 \%$ & & \\
\hline \multicolumn{6}{|l|}{ Sector de actividad } \\
\hline Agricultura (NACE: $a-b)$ & $7,1 \%$ & $2,0 \%$ & $3,3 \%$ & \multirow{5}{*}{52,18} & \multirow{5}{*}{0,000} \\
\hline Industria (NACE: c-f) & $24,5 \%$ & $24,6 \%$ & $29,8 \%$ & & \\
\hline Servicios (NACE: $g-k$ y $m-q$ ) & $59,7 \%$ & $68,0 \%$ & $66,1 \%$ & & \\
\hline Administración Pública (NACE: I) & $8,7 \%$ & $5,4 \%$ & $0,8 \%$ & & \\
\hline Otros servicios (NACE: $\mathrm{m}-\mathrm{q}$ ) & $25,1 \%$ & $29,6 \%$ & $27,3 \%$ & & \\
\hline \multicolumn{6}{|l|}{ Tipo de sector } \\
\hline Privado & $68,5 \%$ & $82,8 \%$ & $91,4 \%$ & \multirow{2}{*}{79,458} & \multirow{2}{*}{0,000} \\
\hline Público & $31,5 \%$ & $17,2 \%$ & $8,6 \%$ & & \\
\hline \multicolumn{6}{|l|}{ Tipo de ocupación } \\
\hline Autónomos & $12,0 \%$ & $10,4 \%$ & $8,8 \%$ & \multirow{3}{*}{3,485} & \multirow{3}{*}{ n.s. } \\
\hline Empresario con trabajadores & $3,5 \%$ & $4,7 \%$ & $4,2 \%$ & & \\
\hline Empleado por cuenta ajena & $84,5 \%$ & $84,9 \%$ & $87,0 \%$ & & \\
\hline \multicolumn{6}{|l|}{ Tipo de trabajo (*) } \\
\hline Trabajadores cuello blanco & $64,2 \%$ & $61,9 \%$ & $42,1 \%$ & \multirow{2}{*}{57,59} & \multirow{2}{*}{0,000} \\
\hline Trabajadores cuello azul & $35,8 \%$ & $38,1 \%$ & $57,9 \%$ & & \\
\hline
\end{tabular}

Fuente: elaboración propia.

(*) La división entre trabajadores de cuello blanco y cuello azul se ha efectuado en base a la clasificación nacional de ocupaciones (CNO), asignando los dígitos 1-5 a los empleados de cuello blanco y los dígitos 6 a 9 a los trabajadores de cuello azul. 


\subsection{I.2. Condiciones de trabajo}

La IV Encuesta Europea de Condiciones de Trabajo cubre numerosos aspectos relativos a la forma de organización y distribución del tiempo de trabajo así como de otros derechos y obligaciones en el desempeño de la actividad laboral. Todos estos elementos constituyen dimensiones clave a la hora de analizar las condiciones de trabajo, ya que atañe al corazón de la relación laboral afectando a la calidad del empleo.

Bajo esta perspectiva, en la tabla 2 se aprecian algunas diferencias significativas entre los tres colectivos de trabajadores objeto de investigación en el presente estudio. En primer lugar, se advierte una clara discriminación intergrupos en cuanto a la estabilidad del empleo. Por término medio, en la UE-27 el 78,0\% de los empleados tiene un contrato de trabajo indefinido, sin embargo, existen diferencias sustanciales al desgranar esta circunstancia entre los diferentes grupos. En este sentido, la mayor precariedad laboral de los inmigrantes extracomunitarios es nítida, ya que sólo el $54,1 \%$ del total disfruta de un contrato de trabajo indefinido frente al $80,6 \%$ de nacionales y al $83,3 \%$ de inmigrantes intracomunitarios. De este modo, un $23,1 \%$ de los inmigrantes extracomunitarios tiene firmado un contrato temporal con su empresa mientras que un $22,8 \%$ reconoce que está trabajando sin ningún tipo de vinculación contractual $(6,1 \%$ entre los nacionales y $5,8 \%$ entre los inmigrantes intracomunitarios).

Algunos estudios asocian la inestabilidad con el tipo de jornada, encontrándose menor estabilidad en aquellos empleados que trabajan a tiempo parcial. Sin embargo, este no es el caso que nos ocupa, ya que en la tabla 2 se constata que no existen diferencias significativas entre los tres colectivos objeto de análisis pues en los tres casos aproximadamente ocho de cada diez ocupados trabajan a tiempo completo' ${ }^{14}$.

Donde sí se aprecian algunas diferencias es en la forma de organización del tiempo de trabajo. Por un lado, se advierte que los inmigrantes extracomunitarios trabajan más horas semanales que los nacionales y los inmigrantes intracomunitarios: el $34,6 \%$ declara dedicar más de 40 horas a la semana frente al $25,4 \%$ y el $20,3 \%$ respectivamente ${ }^{15}$. Por otro, también se han hallado diferencias estadísticamente

\footnotetext{
${ }^{14}$ Las estadísticas a nivel global de la Unión Europea indican que la incidencia del trabajo a tiempo parcial se sitúa en torno al $17 \%$, cifras muy parecidas a las obtenidas en este estudio.

${ }^{15}$ En la UE se observa desde 1991 una tendencia a la reducción de las horas de trabajo remunerado
} 
significativas relativas al trabajo en sábado (casi dos de cada tres inmigrantes extracomunitarios trabaja algún sábado al mes, frente al 52,4\% de intracomunitarios y al $51,7 \%$ de nacionales en esta situación). Finalmente, aunque los datos aportados en la tabla 2 parecen indicar una mayor propensión de los inmigrantes extracomunitarios al trabajo nocturno y dominical, y menor en lo que respecta al sometimiento a un sistema de turnos, en ninguno de estos casos se puede aseverar que esas diferencias sean significativas desde un punto de vista estadístico.

En otro orden de cosas hay que reseñar que la naturaleza del trabajo que desempeña un empleado se relaciona de forma directa con la calidad del mismo. La delicada situación de muchos inmigrantes -sobre todo extracomunitarios-en la Unión Europea motiva que con independencia de otros factores estas personas se vean obligadas a aceptar trabajos poco gratificantes. Este hecho se constata en la tabla 2, donde se aprecia que los inmigrantes procedentes de países no miembros de la UE desempeñan tareas más simples, más monótonas y sobre las que ejercen un menor grado de control, reservando los puestos más complejos, menos monótonos y con mayor grado de autonomía a los inmigrantes intracomunitarios $y$, sobre todo, a los empleados nacionales.

Un último aspecto estrechamente relacionado con la calidad del empleo es el sistema retributivo del que disfrutan los trabajadores, configurándose como un elemento crucial para comprender y explicar las condiciones de trabajo dada la vinculación directa entre la remuneración que se percibe y la naturaleza del trabajo que se realiza. Debido a la dificultad que existe para recoger datos sobre este asunto -y más aún en estudios de ámbito internacional -, la IV Encuesta Europea de Condiciones de Trabajo pregunta a los empleados sobre su posición relativa en una escala de 1 a 10 puntos que se corresponde con los deciles salariales correspondientes al país donde se desarrolla la entrevista. Con esta metodología, en la tabla 2 se pone de manifiesto que el $70,8 \%$ de los inmigrantes extracomunitarios obtiene unos ingresos mensuales por debajo de la mediana del país donde prestan sus servicios profesionales, muy alejados por tanto del $57,0 \%$ de inmigrantes intracomunitarios y del $50,9 \%$ de autóctonos en esta misma situación.

Las desigualdades identificadas entre el colectivo de trabajadores extracomunitarios son aún más reveladoras si se tiene en cuenta que no existen diferencias en la parte con mayor peso en los ingresos mensuales, que es el salario fijo que

que sólo se ralentizó en 2005 como consecuencia de la ampliación ocurrida en 2004. Aún así, la proporción de personas que trabajan más de 40 horas semanales ha disminuido considerablemente desde 2001. 
percibe el empleado. En los tres colectivos investigados, la proporción de trabajadores que percibe un sueldo fijo es superior al $90 \%$ sin que existan diferencias estadísticas entre ellos. Algo similar ocurre con la retribución variable vinculada al rendimiento individual (sólo uno de cada diez ocupados percibe este tipo de compensación sin que exista un comportamiento diferenciado entre los grupos) y con la retribución mediante el reparto de acciones de la propia empresa: una práctica escasamente utilizada por las empresas europeas y que afecta de igual modo tanto a trabajadores nacionales como inmigrantes.

Otras políticas de compensación sí actúan como factores discriminantes entre colectivos, sobre todo en lo que se refiere al de inmigrantes ajenos a la UE con respecto a los otros dos. De este modo, la proporción de personas que recibe algún tipo de remuneración variable vinculada a los resultados generales de la empresa (3,2\% frente al $11,8 \%$ en nacionales y $10,2 \%$ en intracomunitarios), al rendimiento del equipo de trabajo ( $1,7 \%$ frente al $7,1 \%$ y $6,5 \%$, respectivamente) o que disfrutan de algún tipo de compensación de otra naturaleza, como podría ser la remuneración en especie o la percepción de ciertos beneficios sociales, $18,5 \%$ frente al $13,2 \%$ y al $23,1 \%$, respectivamente), es muy inferior entre los inmigrantes extracomunitarios en comparación con los otros dos grupos que presentan un comportamiento más homogéneo.

TABLA 2. Condiciones de trabajo

\begin{tabular}{|c|c|c|c|c|c|}
\hline Variables & Nacional & $\begin{array}{l}\text { Inmigr. intra- } \\
\text { comunitario }\end{array}$ & $\begin{array}{l}\text { Inmigr. extra- } \\
\text { comunitario }\end{array}$ & $\chi^{2}$ & Sig. \\
\hline \multicolumn{6}{|l|}{ Tipo de contrato } \\
\hline Indefinido & $80,6 \%$ & $83,3 \%$ & $54,1 \%$ & \multirow{3}{*}{106,895} & \multirow{3}{*}{0,000} \\
\hline Temporal & $13,4 \%$ & $10,9 \%$ & $23,1 \%$ & & \\
\hline Sin contrato & $6,1 \%$ & $5,8 \%$ & $22,8 \%$ & & \\
\hline \multicolumn{6}{|l|}{ Dedicación } \\
\hline Tiempo parcial & $17,4 \%$ & $20,9 \%$ & $16,6 \%$ & \multirow{2}{*}{3,027} & \multirow{2}{*}{ n.s. } \\
\hline Tiempo completo & $82,6 \%$ & $79,1 \%$ & $83,4 \%$ & & \\
\hline \multicolumn{6}{|l|}{ Horas semanales } \\
\hline Hasta 20 horas & $10,4 \%$ & $12,2 \%$ & $8,3 \%$ & \multirow{3}{*}{24,276} & \multirow{3}{*}{0,000} \\
\hline De 21 a 40 horas & $64,2 \%$ & $67,5 \%$ & $57,1 \%$ & & \\
\hline Más de 40 horas & $25,4 \%$ & $20,3 \%$ & $34,6 \%$ & & \\
\hline \multicolumn{6}{|l|}{ Trabajo nocturno } \\
\hline Nunca & $79,5 \%$ & $80,0 \%$ & $75,9 \%$ & \multirow{2}{*}{2,677} & \multirow[b]{2}{*}{ n.s. } \\
\hline Alguna vez & $20,5 \%$ & $20,0 \%$ & $24,1 \%$ & & \\
\hline
\end{tabular}




\begin{tabular}{|c|c|c|c|c|c|}
\hline Variables & Nacional & $\begin{array}{l}\text { Inmigr. intra- } \\
\text { comunitario }\end{array}$ & $\begin{array}{l}\text { Inmigr. extra- } \\
\text { comunitario }\end{array}$ & $\chi^{2}$ & Sig. \\
\hline \multicolumn{6}{|l|}{ Trabajo en sábado } \\
\hline Nunca & $48,3 \%$ & $47,6 \%$ & $35,4 \%$ & \multirow{2}{*}{19,980} & \multirow{2}{*}{0,000} \\
\hline Alguna vez & $51,7 \%$ & $52,4 \%$ & $64,6 \%$ & & \\
\hline \multicolumn{6}{|l|}{ Trabajo en domingo } \\
\hline Nunca & $69,3 \%$ & $68,6 \%$ & $65,3 \%$ & \multirow{2}{*}{1,926} & \multirow{2}{*}{ n.s. } \\
\hline Alguna vez & $30,7 \%$ & $31,4 \%$ & $34,7 \%$ & & \\
\hline \multicolumn{6}{|l|}{ Trabajo a turnos } \\
\hline Nunca & $17,2 \%$ & $16,7 \%$ & $18,6 \%$ & \multirow{2}{*}{0,604} & \multirow{2}{*}{ n.s. } \\
\hline Alguna vez & $82,8 \%$ & $83,3 \%$ & $81,4 \%$ & & \\
\hline \multicolumn{6}{|l|}{ Tareas complejas } \\
\hline Sí & $64,4 \%$ & $57,0 \%$ & $46,5 \%$ & \multirow{2}{*}{31,425} & \multirow{2}{*}{0,000} \\
\hline No & $35,6 \%$ & $43,0 \%$ & $53,5 \%$ & & \\
\hline \multicolumn{6}{|l|}{ Tareas monótonas } \\
\hline Sí & $42,2 \%$ & $46,8 \%$ & $54,3 \%$ & \multirow{2}{*}{14,638} & \multirow{2}{*}{0,001} \\
\hline No & $57,8 \%$ & $53,2 \%$ & $45,7 \%$ & & \\
\hline \multicolumn{6}{|c|}{ Flexibilidad en métodos trabajo } \\
\hline Sí & $67,6 \%$ & $68,5 \%$ & $58,4 \%$ & \multirow{2}{*}{12,668} & \multirow{2}{*}{0,002} \\
\hline No & $32,4 \%$ & $31,5 \%$ & $41,6 \%$ & & \\
\hline \multicolumn{6}{|l|}{ Ingresos mensuales } \\
\hline Por encima de la mediana & $49,1 \%$ & $43,0 \%$ & $29,2 \%$ & \multirow{2}{*}{36,666} & \multirow{2}{*}{0,003} \\
\hline Por debajo de la mediana & $50,9 \%$ & $57,0 \%$ & $70,8 \%$ & & \\
\hline \multicolumn{6}{|l|}{ Salario fijo } \\
\hline Sí & $95,0 \%$ & $93,8 \%$ & $91,6 \%$ & \multirow{2}{*}{3,876} & \multirow{2}{*}{ n.s. } \\
\hline No & $5,0 \%$ & $6,2 \%$ & $8,4 \%$ & & \\
\hline \multicolumn{6}{|c|}{ Retribución variable (rendimiento individuo) } \\
\hline Sí & $10,1 \%$ & $10,5 \%$ & $10,9 \%$ & \multirow{2}{*}{0,157} & \\
\hline No & $89,9 \%$ & $89,5 \%$ & $89,1 \%$ & & n.s. \\
\hline Retribución variable (rendi & niento emp & resa) & & & \\
\hline Sí & $11,8 \%$ & $10,2 \%$ & $3,2 \%$ & 21876 & 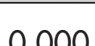 \\
\hline No & $88,2 \%$ & $89,8 \%$ & $96,8 \%$ & $21,8 / 6$ & 0,000 \\
\hline Retribución variable (rendi & niento equi & po de trabajol & & & \\
\hline Sí & $7,1 \%$ & $6,5 \%$ & $1,7 \%$ & 55 & (1000 \\
\hline No & $92,9 \%$ & $93,5 \%$ & $98,3 \%$ & 53 & 0,001 \\
\hline Retribución con acciones en & presa & & & & \\
\hline Sí & $2,0 \%$ & $2,5 \%$ & $0,7 \%$ & & \\
\hline No & $98,0 \%$ & $97,5 \%$ & $99,3 \%$ & $3,6 / 5$ & n.s. \\
\hline Retribución de otra natura & $z a$ & & & & \\
\hline Sí & $13,2 \%$ & $23,1 \%$ & $8,5 \%$ & & הח \\
\hline No & $86,8 \%$ & $76,9 \%$ & $91,5 \%$ & $32,1 / 0$ & 0,000 \\
\hline
\end{tabular}

Fuente: elaboración propia. 


\subsection{I.3. Discriminación y satisfacción}

Diversos estudios ponen de manifiesto que los comportamientos disfuncionales asociados a la discriminación en el puesto de trabajo provocan necesariamente efectos dañinos sobre el individuo que los padece, en especial sobre el nivel de satisfacción, pero también sobre el entorno de trabajo y el rendimiento general de la organización donde se toleran tales conductas.

En este sentido, la exposición de la población inmigrante a la discriminación es probable que sea más elevada, dadas las particularidades que caracterizan a este colectivo. Los resultados de la tabla 3 confirman de modo inmediato lo que se presuponía. Mientras que son muy pocos los nacionales que se han sentido en algún momento discriminados por razón de nacionalidad $(0,6 \%)$, de etnia $(0,4 \%)$ o por motivos religiosos $(0,6 \%)$, estos porcentajes aumentan de forma significativa cuando se pregunta a los inmigrantes, sobre todo si estos provienen de países que no forman parte de la Unión Europea. La discriminación proviene especialmente de las diferencias por razón de nacionalidad (un 16,8\% de inmigrantes extracomunitarios y un 7,5\% de intracomunitarios se han sentido en algún momento rechazados por este motivo) y de etnia (particularmente entre los extracomunitarios: 11,9\% del total), sin embargo, los prósperos ciudadanos europeos parecen algo menos intransigentes con las diferencias de naturaleza religiosa.

En otro orden de cosas hay que indicar que discriminación y satisfacción constituyen dos conceptos estrechamente vinculados entre sí y ambos, a su vez, forman parte del marco de condiciones laborales donde está sumergida la actividad laboral. Hoy día, el trabajo ocupa una parte muy significativa del tiempo disponible para la mayoría de ciudadanos adultos. A la vez, la actividad laboral genera sentimientos de identidad y utilidad social. Por consiguiente, la satisfacción con el trabajo constituye una variable de gran importancia para el bienestar del individuo directamente relacionada con las condiciones laborales de las que disfruta este. Por consiguiente, un empleado con "un buen trabajo" -bien pagado, estable, con un entorno agradable sin discriminación de ningún tipo y una actividad motivadora...- debería traducirse en niveles más elevados de satisfacción general. No obstante, dado el panorama dibujado hasta el momento cabe esperar que los inmigrantes, sobre todo extracomunitarios, muestren un grado de satisfacción inferior a la de los dos colectivos restantes.

En la tabla 3 se constata tal aseveración. En las últimas tres Encuestas Europeas de Condiciones de Trabajo, realizadas en 1995, 2000 y 2005, se pone de manifiesto que aproximadamente ocho de cada diez ocupados se muestra satisfecho o muy satisfecho con su empleo. En este trabajo se han obtenido resultados similares 
entre el colectivo de empleados nacionales $(78,2 \%)$ e inmigrantes intracomunitarios $(80,3 \%)$, pero la satisfacción general disminuye cuando se interroga a los inmigrantes procedentes de países ajenos a la UE, algo razonable a la vista de los resultados expuestos hasta el momento.

Al desgranar la sensación global de satisfacción en factores se aprecia que la insatisfacción se agudiza en algunos aspectos concretos, aunque en todo momento se mantiene la misma tendencia: los inmigrantes extracomunitarios se muestran menos satisfechos, mientras que el comportamiento de nacionales e inmigrantes procedentes de países miembros de la UE es muy similar. Así, los ocupados extracomunitarios exhiben principalmente su descontento con las expectativas de carrera profesional (casi tres de cada cuatro declaran estar insatisfechos o muy insatisfechos), con la retribución que perciben (uno de cada dos) y con las oportunidades de aprendizaje y desarrollo profesional (casi el $50 \%$ ), aunque las mayores diferencias con respecto a los otros dos grupos objeto de análisis se manifiestan en la seguridad laboral: casi uno de cada tres inmigrantes extracomunitarios piensa que puede perder su empleo en los próximos seis meses, frente al 18,2\% de nacionales y al $15,6 \%$ de intracomunitarios.

Como en muchas otras ocasiones, el colectivo de inmigrantes intracomunitario se parece más al de nacionales que al de extranjeros ajenos a la UE, a excepción del sentimiento de pertenencia a la organización, donde ambos grupos de inmigrantes muestran un grado similar de satisfacción, mostrándose bastante inferior al declarado por los empleados nacionales.

\section{TABLA 3. Discriminación y satisfacción}

\begin{tabular}{|c|c|c|c|c|c|}
\hline Variables & Nacional & $\begin{array}{l}\text { Inmigr. intra- } \\
\text { comunitario }\end{array}$ & $\begin{array}{l}\text { Inmigr. extra- } \\
\text { comunitario }\end{array}$ & $\chi^{2}$ & Sig. \\
\hline \multicolumn{6}{|c|}{ DISCRIMINACIÓN } \\
\hline \multicolumn{6}{|c|}{ Por razón de nacionalidad } \\
\hline Sí & $0,6 \%$ & $7,5 \%$ & $16,8 \%$ & \multirow{2}{*}{84,887} & \multirow{2}{*}{0,000} \\
\hline No & $99,4 \%$ & $92,5 \%$ & $83,2 \%$ & & \\
\hline \multicolumn{6}{|l|}{ Por razón éfnica } \\
\hline Sí & $0,4 \%$ & $3,4 \%$ & $11,9 \%$ & \multirow{2}{*}{68,523} & \multirow{2}{*}{0,000} \\
\hline No & $99,6 \%$ & $96,6 \%$ & $88,1 \%$ & & \\
\hline \multicolumn{6}{|l|}{ Por razón religiosa } \\
\hline Sí & $0,6 \%$ & $1,2 \%$ & $4,4 \%$ & \multirow{2}{*}{19,277} & \multirow{2}{*}{0,000} \\
\hline No & $99,4 \%$ & $98,8 \%$ & $95,6 \%$ & & \\
\hline
\end{tabular}




\begin{tabular}{|c|c|c|c|c|c|}
\hline Variables & Nacional & $\begin{array}{l}\text { Inmigr. intra- } \\
\text { comunitario }\end{array}$ & $\begin{array}{l}\text { Inmigr. extra- } \\
\text { comunitario }\end{array}$ & $\chi^{2}$ & Sig. \\
\hline \multicolumn{6}{|c|}{ SATISFACCIÓN } \\
\hline \multicolumn{6}{|c|}{ Satisfacción en general } \\
\hline Sí & $78,2 \%$ & $80,3 \%$ & $71,2 \%$ & \multirow{2}{*}{11,543} & \multirow{2}{*}{0,000} \\
\hline No & $21,8 \%$ & $19,7 \%$ & $28,8 \%$ & & \\
\hline \multicolumn{6}{|c|}{ Seguridad en el empleo } \\
\hline Sí & $81,8 \%$ & $84,4 \%$ & $69,3 \%$ & \multirow{2}{*}{27,995} & \multirow{2}{*}{0,001} \\
\hline No & $18,2 \%$ & $15,6 \%$ & $30,7 \%$ & & \\
\hline \multicolumn{6}{|c|}{ Satisfacción con retribución } \\
\hline Sí & $55,4 \%$ & $60,5 \%$ & $49,3 \%$ & \multirow{2}{*}{8,699} & \multirow{2}{*}{0,013} \\
\hline No & $44,6 \%$ & $39,5 \%$ & $50,7 \%$ & & \\
\hline \multicolumn{6}{|c|}{ Expectativas carrera profesional } \\
\hline Sí & $40,7 \%$ & $41,0 \%$ & $27,2 \%$ & \multirow{2}{*}{19,794} & \multirow{2}{*}{0,000} \\
\hline No & $59,3 \%$ & $59,0 \%$ & $72,8 \%$ & & \\
\hline \multicolumn{6}{|c|}{ Sentimiento pertenencia organiz. } \\
\hline Sí & $79,4 \%$ & $67,8 \%$ & $67,7 \%$ & \multirow{2}{*}{17,880} & \multirow{2}{*}{0,000} \\
\hline No & $20,6 \%$ & $32,2 \%$ & $32,3 \%$ & & \\
\hline \multicolumn{6}{|c|}{ Oportunidad aprendizaje/desarrollo } \\
\hline Sí & $66,9 \%$ & $66,5 \%$ & $52,1 \%$ & \multirow{2}{*}{23,252} & \multirow{2}{*}{0,000} \\
\hline No & $33,1 \%$ & $33,5 \%$ & $47,9 \%$ & & \\
\hline \multicolumn{6}{|c|}{ Relaciones de amistad en trabajo } \\
\hline Sí & $87,7 \%$ & $87,2 \%$ & $81,4 \%$ & \multirow{2}{*}{7,847} & \multirow{2}{*}{0,020} \\
\hline No & $12,3 \%$ & $12,8 \%$ & $18,6 \%$ & & \\
\hline
\end{tabular}

Fuente: elaboración propia.

\subsubsection{Análisis multivariante}

Tras el análisis bivariante inicial, a continuación se considera oportuno plantear un modelo de regresión logística que ayude a determinar el efecto conjunto de las diferentes categorías de variables utilizadas hasta el momento sobre la nacionalidad de los trabajadores encuestados ${ }^{16}$.

${ }^{16}$ La metodología utilizada para el cumplimiento de los objetivos de este apartado se fundamenta en el modelo de regresión logística binaria, un caso particular de los denominados modelos de regresión con respuesta dicotómica. Esta técnica estadística permite determinar la probabilidad de ocurrencia del 
Para la construcción del modelo de regresión logística se han adoptado algunas decisiones metodológicas que se resumen a continuación. En primer lugar, se ha optado por estudiar únicamente a los trabajadores nacionales e inmigrantes extracomunitarios, ya que el colectivo de inmigrantes intracomunitarios ha demostrado ser extremadamente confuso dada la heterogeneidad de las personas que lo integran ${ }^{17}$. Debido a esta circunstancia, se repitió el análisis bivariante para constatar si se produce algún cambio significativo al considerar únicamente a dos grupos en el mismo. Los resultados obtenidos coinciden exactamente con los comentados en el apartado previo, con la única excepción de la variable formación que en este caso no presenta diferencias estadísticamente significativas y que, por consiguiente, no se tendrá en cuenta a la hora de construir el modelo de regresión. Finalmente hay que indicar que para estimar el modelo se ha optado

suceso investigado frente a la probabilidad de ocurrencia del suceso contrario. La forma más habitual de presentar este modelo viene dada por:

$$
\frac{p}{1-p}=e^{\beta_{0}+\sum_{i=1}^{k} \beta_{i} X_{i}}
$$

El primer miembro de esta igualdad se denomina ratio de riesgo -o también "odds ratio" (OR)- y representa la probabilidad relativa del suceso investigado frente a su no ocurrencia. Así, una OR cuyo valor fuera $\mathrm{x}$ indicaría que es $\mathrm{x}$ veces más probable que un sujeto sea inmigrante frente a nacional. Desde este punto de vista, la interpretación de los coeficientes del modelo resulta sencilla. Una vez elegida la variable $X_{\text {y }}$ el resto de las variables independientes, ante cualquier incremento unitario de este predictor la razón entre las odds ratio vendrá dada por:

$$
\Delta \frac{p}{1-p}=e^{\beta_{\jmath}}
$$

De esta forma, si $\beta>0$, el incremento en la ratio de riesgo será mayor que 1 , lo que significa un incremento en la probabilidad de ocurrencia del suceso investigado. Como en cualquier otro modelo estadístico, el de regresión logística admite diversos contrastes de hipótesis que determinan su validez, tanto en términos globales como individuales. Los primeros evalúan en su conjunto la posibilidad de que realmente el fenómeno investigado pueda ser modelado mediante una expresión del tipo elegido, mientras que los segundos, cuya validez está supeditada a los primeros, examinan la conveniencia de incluir o no cada una de las variables en el modelo considerado. En este trabajo se empleará como medida global el índice de bondad de ajuste de Hosmer-Lemeshow, cuyo valor será más reducido cuanto más ajustado sea el modelo y, por consiguiente, tanto más significativo cuanto mayor sea el correspondiente $p$-valor. Para los análisis individuales se utilizará el test de Wald, similar en su interpretación al estadístico templeado habitualmente en los modelos de regresión lineal: mayor significación para aquellas variables en las que el valor del estadístico sea elevado y, por tanto, cuanto menor sea el $p$-valor.

${ }_{17}$ Dependiendo del país de procedencia, estos pueden disfrutar de unas condiciones laborales similares a las de los ocupados autóctonos o a las de los inmigrantes ajenos a la UE. 
por el método por pasos adelante RV, usando todas las variables predictoras que han resultado significativas a partir del análisis bivariante. Con este procedimiento se evalúa qué combinación de variables es la más eficiente en la explicación de la nacionalidad del individuo investigado.

En la tabla 4 se presentan los resultados de la estimación mediante regresión logística de los factores laborales que determinan la nacionalidad del trabajador en la Unión Europea. En primer lugar hay que destacar que el estadístico de contraste aplicado para evaluar la eficiencia del modelo en su conjunto indica que existen razones suficientes para aceptar la validez del mismo ${ }^{18}$, es decir, para afirmar que el hecho de que un trabajador sea nacional o inmigrante extracomunitario puede ser satisfactoriamente explicado por el conjunto de variables consideradas en la presente investigación. Además hay que destacar que las variables utilizadas presentan una importante capacidad de generalización del modelo -tal y como se comprueba al comparar las observaciones que han sido clasificadas correctamente, tanto de forma general como para cada uno de los colectivos investigados- lo que viene a demostrar su eficacia predictora. El modelo de regresión logística que se presenta en la tabla 4 clasifica correctamente al $76,2 \%$ de los casos, observándose un buen equilibrio entre ambos grupos: inmigrantes extracomunitarios $(74,9 \%)$ y trabajadores nacionales $(77,5 \%)$.

Como se puede apreciar en este modelo general, en comparación con los empleados nacionales, la probabilidad de que un individuo proceda de un país extracomunitario es mayor entre los ocupados que trabajan en el sector privado -principalmente en la industria o los servicios-, desempeñando una actividad de las calificadas como de "cuello azul" con contratos temporales y trabajando más de 40 horas semanales. Además, los inmigrantes perciben unos ingresos por debajo de la mediana del país y no tienen acceso a ningún tipo de compensación vinculada al rendimiento de la empresa en la que prestan sus servicios. Por último, resulta más probable que estas personas se hayan sentido discriminados en algún momento por motivos étnicos o como consecuencia de su nacionalidad de origen ${ }^{19}$.

\footnotetext{
${ }^{18}$ La prueba de Hosmer y Lemeshow, utilizada para este fin, presenta los resultados siguientes: ChiCuadrado: 241,565; Sig. 0,000.

${ }^{19}$ Todos estos resultados son significativos en el nivel del 1\%. Para este nivel de significación, el modelo de regresión logística indica que el resto de variables que de forma independiente habían mostrado una relación significativa con la nacionalidad dejan de tenerla cuando se trata de evaluar su impacto de forma conjunta.
} 
A pesar de todo, el impacto de cada una de las variables significativas en la probabilidad de tener una $u$ otra nacionalidad difiere sustancialmente de unas a otras, tal y como indica el análisis de los intervalos de confianza obtenidos para las correspondientes "odds ratios" (ver tabla 4). De esta manera, el efecto más intenso se aprecia en relación con la discriminación étnica, ya que un individuo que se haya sentido discriminado por este motivo en su trabajo es casi 19 veces más probable que sea inmigrante que autóctono. Siguiendo en orden de importancia, a bastante distancia aparece el efecto de la discriminación por motivos de nacionalidad, con un cociente de "odds ratios" de 7,521. Como se indicaba anteriormente, el sector de actividad también contribuye a caracterizar el origen del empleado. En este caso, la OR correspondiente a los inmigrantes extracomunitarios, en comparación con la de los ocupados nacionales, es del $651,2 \%$ en el sector servicios y del $454,0 \%$ en el sector industrial, lo que pone de manifiesto unas mayores tasas de ocupación de los extranjeros no comunitarios en estos sectores productivos. Algo parecido ocurre al analizar la influencia de la naturaleza del sector de actividad, de tal modo que trabajar en el sector privado aumenta la probabilidad relativa de ser inmigrante en un $374,5 \%$. Como en los casos anteriores existe un intervalo de confianza muy amplio, ya que el límite superior para la razón evaluada sobrepasa el 638,9\% mientras que en el extremo inferior esta misma razón se sitúa en el $219,5 \%$. O sea, que la probabilidad de que una persona que trabaje en el sector privado sea extracomunitaria -en comparación con los que prestan servicios en algún tipo de administración pública- es algo más del doble en el mejor de los casos y se multiplica por seis en la hipótesis más negativa, poniendo de manifiesto las restricciones que encuentran los extranjeros para acceder al empleo público. En valores similares se mueve la probabilidad en lo que respecta al tipo de trabajo desempeñado. La OR correspondiente a esta variable $(3,472$ con un intervalo de confianza situado entre 2,111 y 5,712$)$ sugiere que los empleos de "cuello blanco", generalmente de mayor prestigio social, se reservan a los trabajadores nacionales, mientras que los inmigrantes deben asumir tareas de "cuello azul", posiblemente de menor cualificación y con condiciones laborales y retributivas más precarias.

El análisis de las "odds ratios" asociadas al resto de variables confirma este último argumento. Así, un trabajador inmigrante tiene cuatro veces menos probabilidades de percibir algún tipo de retribución vinculada al rendimiento de la empresa que uno nacional, mientras que es mucho más probable que sus ingresos se sitúen por debajo de la mediana (con un incremento en OR que alcanza casi los tres puntos y un intervalo de confianza que oscila entre 1,907 y 4,706). Además, una persona cuya jornada de trabajo semanal sea más prolongada, superando las cuarenta horas habituales, es el doble de probable que sea extranjero. Finalmente, 
el modelo de regresión logística también pone de manifiesto las dificultades que encuentran los inmigrantes para acceder al empleo indefinido. En este sentido, la probabilidad relativa de que una persona con contrato indefinido proceda de un país extracomunitario es del $40,7 \%$ en comparación con los ocupados nacionales, situación que alcaza el $63,3 \%$ en el mejor de los casos y desciende al $26,2 \%$ en la hipótesis más negativa.

\section{TABLA 4. Regresión logística: factores que determinan la nacionalidad del ocupado en la Unión Europea e intervalo de confianza de odds ratios}

\begin{tabular}{|l|c|c|c|c|c|c|}
\hline \multicolumn{4}{|c|}{ Variables en el modelo } & \multicolumn{4}{c|}{$\begin{array}{c}\text { Odds ratios } \\
\text { I.C. 95\% para OR }\end{array}$} \\
\hline & B & E.T. & Wald & OR & Inferior & Superior \\
\hline S. Industrial (0: No; 1: Sí) & 1,513 & 0,449 & 11,356 & 4,540 & 1,883 & 10,946 \\
\hline S. Servicios (0: No; 1: Sí) & 1,874 & 0,433 & 18,726 & 6,512 & 2,787 & 15,214 \\
\hline Tipo sector (0: S.Público; 1: S.Privado) & 1,320 & 0,273 & 23,460 & 3,745 & 2,195 & 6,389 \\
\hline $\begin{array}{l}\text { Tipo trabajo (0: Cuello blanco; 1: } \\
\text { Cuello azul) }\end{array}$ & 1,245 & 0,254 & 24,029 & 3,472 & 2,111 & 5,712 \\
\hline Contrato indefinido (0: No; 1: Sí) & $-0,898$ & 0,225 & 15,953 & 0,407 & 0,262 & 0,633 \\
\hline +40 horas-semana (0: No; 1: Sí) & 0,645 & 0,250 & 6,645 & 1,906 & 1,167 & 3,112 \\
\hline Ingresos (0: >mediana; 1: <mediana) & 1,097 & 0,230 & 22,660 & 2,996 & 1,907 & 4,706 \\
\hline $\begin{array}{l}\text { Retribuc. según rendimiento empresa } \\
\text { (0: Sí; 1: No) }\end{array}$ & 1,405 & 0,424 & 10,992 & 4,077 & 1,776 & 9,356 \\
\hline Discrim.nacionalidad (0: No; 1: Sí) & 2,018 & 0,740 & 7,428 & 7,521 & 1,762 & 32,094 \\
\hline Discrim.étnica (0: No; 1: Sí) & 2,940 & 1,259 & 5,454 & 18,921 & 1,604 & 223,135 \\
\hline Constante & $-5,175$ & 0,722 & 51,348 & 0,006 & & \\
\hline$\chi^{2}$ Test de eficiencia. Modelo completo & 241,565 & & & & & \\
\hline Grados de libertad & 11 & & & & & \\
\hline Nivel de significación & 0,00 & & & & & \\
\hline$\%$ Correcto de predicción & & & & & & \\
\hline Modelo completo & $76,2 \%$ & & & & & \\
\hline Modelo inmigrantes extracomunitarios & $74,9 \%$ & & & & & \\
\hline Modelo nacionales & $77,5 \%$ & & & & & \\
\hline
\end{tabular}

Fuente: elaboración propia. 


\section{Conclusiones}

La libre circulación de personas en el ámbito de la Unión Europea, que incluye el derecho a vivir y trabajar en cualquier otro estado miembro, constituye uno de los derechos fundamentales garantizados por el Tratado de Roma de 1957. Más recientemente, el Consejo Europeo de Lisboa de marzo de 2000 estableció una agenda de trabajo donde se fijó un nuevo objetivo estratégico para la próxima década: transformar a la Unión Europea en la economía basada en el conocimiento más competitiva y dinámica del mundo, capaz de crecer económicamente de manera sostenible con más y mejores empleos y con mayor cohesión social. La creación de un mercado europeo de trabajo con una elevada movilidad entre países constituye sin duda un buen paso para alcanzar estos objetivos. Para apoyar esta estrategia se creó EURES, una red europea de servicios para el empleo que garantizaría y haría posible la libre circulación de trabajadores dentro del Espacio Económico Europeo, al mismo tiempo que declaró 2006 como Año Europeo de la movilidad de los trabajadores. Pese a todas estas invocaciones, tal y como afirman Dobson y Sennikova (2007), no está tan claro que estos encomiables objetivos sean compartidos por la mayoría de la población ni por algunos estados miembros, especialmente después de la ampliación de 2004. Además, tan loables aspiraciones son aplicables, fundamentalmente, a los ciudadanos de pleno derecho de la Unión Europea, favoreciendo la movilidad dentro de las fronteras pero postergando a un segundo plano a los trabajadores procedentes de países ajenos a la UE. De hecho, en este trabajo se ha constatado que las diferencias entre ocupados nacionales e inmigrantes intracomunitarios son difusas dada la heterogeneidad existente en este último colectivo, diferencias que perdurarán en el tiempo hasta que las políticas de convergencia vayan aproximando el nivel de vida de los últimos países en incorporarse a la media de la UE.

El debate acerca de la inmigración viene de lejos en algunas naciones, mientras que constituye un fenómeno mucho más reciente en otras, pero siempre germina sobre la misma placenta, el recelo hacia el inmigrante, hacia lo diferente, hacia otras razas, etnias, religiones o costumbres alejadas de los valores tradicionales que impregnan a la vieja Europa, tal y como lo ejemplifica el apoyo reciente en referéndum de la mayoría de los suizos - a propuesta del ultraderechista Partido Popular Suizo (SVP-UDC)- de prohibir en la Constitución la erección de minaretes en las mezquitas que se construyan en el país helvético en el futuro.

Pero ese racismo de fondo se enmascara en muchos casos con argumentos de índole económica, acusando a los inmigrantes del deterioro del mercado de trabajo 
nacional, aun cuando no existen evidencias empíricas que confirmen a ciencia cierta tales hipótesis, tal y como refleja la bibliografía sobre este asunto revisada en el apartado 3 del presente trabajo. Por el contrario, sí hay pruebas y estadísticas objetivas que demuestran los efectos beneficiosos de los flujos migratorios sobre las economías de los países receptores, entre otras se pueden destacar las siguientes:

- Aportación neta a la Seguridad Social (los inmigrantes que se insertan al mercado laboral son en su mayoría personas jóvenes y fuertes que gozan de buena salud y están en sus años más productivos, contribuyendo de este modo al mantenimiento de los sistemas de pensiones y salud públicos).

- Mejora de la estructura demográfica de los países receptores (rejuvenecimiento de la población dado el perfil del inmigrante y su mayor tasa de fertilidad).

- Mantenimiento de la actividad productiva y crecimiento económico (incremento del consumo y del ahorro -ya que en general estas personas presentan una mayor propensión marginal a ahorrar-, aumento de la eficiencia económica y la productividad, al transferirse trabajadores de áreas improductivas a sectores productivos de la economía ${ }^{20}$, menores cuellos de botella en la producción, ya que estas personas pueden cubrir puestos de trabajo que por diversas razones el mercado laboral no está en disposición de $\|_{\text {enar }}{ }^{21}$, mayor movilidad geográfica que los trabajadores autóctonos...).

En nuestra opinión, tales argumentos no son suficientes para superar los arraigados prejuicios imperantes en la pávida sociedad europea y ello pese a que, en la mayoría de los casos, los inmigrantes vienen a ocupar un hueco en el mercado laboral que, sobre todo en tiempos de bonanza económica, no están dispuestos a rellenar los ciudadanos nativos. Esta circunstancia se ha constatado en el presente trabajo -sobre todo referida a la inmigración extracomunitaria- con un estudio empírico de ámbito comunitario, donde se ha constatado que las condiciones

20 Un ejemplo muy gráfico es la llegada de trabajadoras que trabajan de empleadas domésticas permitiendo a mujeres, muchas de ellas profesionales, integrarse a la fuerza laboral.

${ }^{21}$ El director del Instituto Nacional de Empleo de Noruega mostraba en 2007 su preocupación por las bajas tasas de desempleo que se manifiestaban en su país, en torno al $2 \%$. Esta circunstancia dificulta la realización de proyectos que requieren de mano de obra, enfriando por consiguiente la economía. Haciendo uso de sus propias palabras: «Nuestra tasa de desempleo comienza a ser contraproducente». En este contexto, el círculo vicioso incremento de costes salariales, aumento de inflación, pérdida de competitividad supone una seria amenaza. 
laborales de estas personas difieren notablemente de las que presentan los europeos autóctonos.

De este modo, mediante un modelo de regresión logística se han puesto de manifiesto en términos probabilísticos los rasgos que caracterizan a la población inmigrante extracomunitaria inserta en el mercado laboral europeo. En este sentido, se puede hablar de un ocupado del sector privado, que trabaja por cuenta ajena con algún tipo de contrato temporal, en la industria o los servicios, en ocupaciones de baja cualificación profesional y con un horario que supera el estándar europeo de las 40 horas semanales. Pese a ello, el inmigrante extracomunitario percibe una remuneración que se sitúa por debajo de la mediana del país receptor, a la vez que queda al margen de los sistemas retributivos que vinculan la compensación con el rendimiento individual. Por consiguiente, no resulta de extrañar que estas personas se hayan sentido en algún momento discriminados por motivos étnicos o de nacionalidad.

Aunque la presente investigación aspira a cambiar esa imagen de "invasión no deseada" que la inmigración genera, con mayor o menor virulencia, en una parte importante de la ciudadanía europea, lo cierto es que si en tiempos de opulencia y prosperidad han sido sobradamente cuestionados, creemos no hay motivos para el optimismo ahora que la crisis económica ha destruido millones de empleos en Europa y los nativos están dispuestos a desempeñar puestos de trabajo que hasta hace poco tiempo repudiaban, encontrándose que muchos de ellos están ocupados por extranjeros, con papeles en el mejor de los casos o por esa hermética bolsa de irregulares en condiciones de marginalidad.

\section{Bibliografía}

AmUedo-Dorantes, C. y de la RiCA, S. (2005). "Immigrants Responsiveness to Labour Market Conditions and its Implications on Regional Disparities: Evidence from Spain". IZA DP 1557, April.

APARICIO, R. y TORNOS, A (2002). El Estado de Bienestar y la inmigración en España. Madrid: Ministerio de Trabajo y Asuntos Sociales.

Argerey, P., Estévez, L., Fernández, M. y Menéndez, E. (2005). El fenómeno de la inmigración en Europa: perspectivas jurídicas y económicas. Dykinson, Madrid.

Acosta, A. y AtienZA, J. (2004). "Migraciones y desarrollo: Estudio de dos casos 
particulares (II): El caso de Ecuador". Documentos de Trabajo, N ${ }^{\circ}$ 3. Madrid: Centro de Estudios de Cooperación al Desarrollo (CECOD).

Aubarell, G y Aragall, X. (2004). "Migraciones y desarrollo: Estudio de dos casos particulares (II): El caso de Marruecos". Documentos de Trabajo, № 3. Madrid: Centro de Estudios de Cooperación al Desarrollo (CECOD).

Bauer, T. y Zimmermann, K. F. (1998). Causes of International Migration: A Survey. En C. Gorter, P. Nijkamp and J. Poot (Eds.): Crossing Borders. Regional and Urban Perspectives on International Migration. Aldershot, pp. 95-127.

BORJAS, G. (1999). The Economic Analysis of Immigration. En Ashenfelter, O. y Card, D. (eds.).

Borjas, G., Freeman, R. y Katz, L. (1997). "How much do Immigration and Trade Affect Labor Market Outcomes". Bookings Papers on Economic Activity, 1:1-90.

BORJAS, G. J. (1994). "The Economics of Immigration. Journal of Economic Literature, vol. XXXII, pp. 1667-1717.

BORJAS, G. J. (1999). "Economic Research on the Determinants of Immigration. Lessons for the European Union". World Bank Technical Paper, n 438.

BorJAs, G. J. (2002). The Impact of Welfare Reform on Immigrant Welfare Use. Center Report. Center of Immigration Studies. Washington, D.C.

CARD, D. (1990). "The Impact of the Mariel Boatlift on the Labor Market". Industrial and Labor Relation Review 43(2), pp: 245-57.

CarRasco, C. (1999). "Mercados de trabajo. Los inmigrantes económicos". Observatorio Permanente de la Inmigración, IMSERSO, Madrid.

Carrasco, R., Jimeno, J. F. y Ortega, A. C. (2004). The Effect of Immigration on the Employment Opportunities of native-Born Workers: Some Evidence for Spain. FEDEA, DT 2004-17, september.

COMIIIÓN EUROPEA (2006). "Report on the Functioning of the Transitional Arrangements set out in the 2003 Accession Treaty (period 1 May 2004 - 30 April 2006)". Communication from the Commission (Com (2006) 48 final).

Commander, S., Heitmueller, A. y Tyson, L. (2006). "Migration Workers and Jobs: A Challenge to the European Social Model". IZA Discussion Paper Series, n 1933. 
CharRo, P. y Benlloch, P. (2006). Guía práctica de contratación laboral de extranjeros. Aranzadi.

de New, J. y ZimmermanN, K. F. (1994). "Native Wage Impacts of Foreign Labor: A Random Effects Panel Analysis". Journal of Population Economics, 7, pp. 177-192.

DoBSON, J, R. y SENNIKOVA, I. (2007). "From fundamental freedom to political and economic "hot potato" in 50 years: Labour mobilitiy and migration within the EU". Journal of Business Economics and Management, Vol. VIII, n 2, pp. 123-136.

DONAGHEY, J. y TEAGUE, P. (2006). "The free movement of workers and social Europe: maintaining the European ideal". Industrial Relations Journal, 36: 6.

EspinOLA, J. R. (2006). "Inmigración y crecimiento de la economía española (2000-2005)". ICADE, n 69.

FERNÁNDEZ, M. (2006). "Inmigración y mercado laboral". ICADE, nº 69.

FRIEDBERG, R. y HUNT, J. (1995). "The Impact of Immigration on Host Country Wages, Employment and Growth". Journal of Economic Perspectives 9 (2), pp. 23-44.

Greenwood, M. y McDowell, J. (1986). "The Factor Market Consequences of U.S. Immigration. Journal of Economic Literature 24 (4), pp. 1738-1772.

HARRIS J. y TodARO, M. (1970). "Migration, Unemployment \& Development: A TwoSector Analysis". American Economic Review, March; 60(1):126-42.

Herrarte, A., Medina, E. y Vicens, J. (2007). "Cambios en la situación laboral de la población española ante el incremento de la inmigración". Ekonomiaz, $n^{\circ} 66$, p. 330-349.

JaEGer, D. (1996). "Degrees Matter: New Evidence on Sheepskin Effects in the Returns to Education". Review of Economics a Statistic 78 (4), pp: 733-740.

LALONDE, R. y TOPEL, R. (1997). "Economic Impact of International Migration and the Economic Performance of Migrants". En Rosenzweig, M. y STARK, O. (eds.), Cap. 14.

LEWIS, W. A. (1954). Economic Development with Unlimited Supplies of Labour. Manchester Sch. Econ. Soc. Stud., May 1954, 22, 139-91. 
MaRTínez, J. L. (2006). "Pensar la integración de los inmigrantes: la sociedad española al comienzo del siglo XXI". Revista de Fomento Social, 61, 361-92.

Massey, D. S., Arango, J., Hugo, G., Kouaoucl, A. Pellegrino, A., Taylor, J. e. (1993). "Theories of International Migration: A Review and Appraisal". Population and Development Review, 19:431-466.

PajARES, M. (2004). Inmigración irregular en Cataluña. CERES, Barcelona.

PIORE, M. (1979). Birds of passage. Migrant Labor and Industrial Societies. University Press, Cambridge, Nueva York.

PISCHKE, J. y VeLING, J. (1997). "Employment Effects of Immigration to Germany: an Analysis Based on Local Labor Markets". Review of Economics and Statistics 79 (4), pp. 594-604.

SANROMÁ, E.; RAMOs, R. y SiMPON, H. (2006). "Inmigración reciente en España: Sobreeducación y asimilación en el mercado de trabajo". IX Encuentro de Economía aplicada. Jaén, junio.

SJAASTAD, L. A. (1962). "The Costs and Returns of Human Migration". The Journal of Political Economy, 70, pp. 80-93.

Winkelmann, R. y Zimmermann, K. F. (1992). "Ageing, Migration and Labour Mobility, Labour Markets in an Ageing Europe". CEPR Discussion Papers 706.

Servicio Jesuita a Migrantes (SJM) (2008). "Inmigrantes: ¿̇lnvasores o ciudadanos? Tópicos y cuestiones sobre la inmigración". Cristianismo y Justicia.

ZIMMERMANN, K. F. (1994). "Algunas lecciones generales sobre el problema europeo de las migraciones". Revista del Instituto de Estudios Económicos, 4, pp. 3-32.

Zimmermann, K. F. (1995). European Migration: Push and Pull. Proceedings of the World Bank Annual Conference on Development Economics 1994, World Bank Economic Review, and World Bank Research Observer, pp. 313-342.

ZimmermanN, K. F. (1995). "Tackling the European Migration Problem". Journal of Economic Perspectives, 9, pp. 45-62.

ZimmermanN, K. F. (2005). "European Labour Mobility: Challenges and Potentials". De Economist, 153-4, pp. 425-50. 